América sin Nombre, n.o 24 (2020): 101-109

DOI 10.14198/AMESN.2020.24-2.09

ISSN: 1577.3442 / eISSN: 1989-9831

Fecha de recepción: 12/03/2019

Fecha de aceptación: 01/04/2019
Modo de citación de este artículo:

Marino-Cicinelli, Simone. "La metáfora fantástica como deconstructora de ideologías. El caso de Bestiaria vida de Cecilia Eudave». La nueva novela latinoamericana sin límites. Lise Segas y Félix Terrones (coordinadores). América sin Nombre, 24 (2020): 101-109, DOI: 10.14198/ AMESN.2020.24-2.09

Link para este artículo: http://dx.doi.org/10.14198/AMESN.2020.24-2.09

\title{
La metáfora fantástica como deconstructora de ideologías. El caso de Bestiaria vida de Cecilia Eudave
}

\author{
Fantastic metaphor as a deconstructor of ideologies. \\ The case of Cecilia Eudave's Bestiaria vida
}

\author{
Simone Marino-Cicinelli* \\ Universidad de Salamanca
}

\begin{abstract}
¿Qué es, entonces, la verdad? Un dinámico tropel de metáforas, metonimias y antropomorfismos.
\end{abstract}

FRIEDRICH NIETZSCHE

La metáfora nos reestructura nuestra visión de las cosas.

Alfredo Marcos

\section{Resumen}

El presente artículo da cuenta de un análisis sobre el concepto de metáfora en la novela Bestiaria vida de la mexicana Cecilia Eudave, que ganó el premio "Juan García Ponce» de 2008. Sostenemos, así, que las representaciones metafóricas son un medio para desenmascarar ideologías sociales posmodernas que se han forjado en la actualidad y que hacen del hombre un «sujeto de rendimiento».

Palabras claves: metáfora, ideología, deconstrucción, inusual, Bestiaria vida.

\begin{abstract}
The present article gives an analysis of metaphorical concepts through the work titled Bestiaria vida, authored by Cecilia Eudave of Mexico. The forementioned work won the "Juan Garcia Ponce» Prize in 2008. We propose, therefore, that metaphorical representations unmask postmodern social ideologies that have been forged in the contemporary society and that make become the men «achievement-subjects».
\end{abstract}

Keywords: metaphor, ideology, deconstruction, unusual, Bestiaria vida.

\footnotetext{
* Cursó el Grado en Lenguas y Culturas Extranjeras por la Universidad de los Estudios Roma Tre y el Máster en Literatura Española e Hispanoamericana, Teoría de la Literatura y Literatura Comparada (especialidad en Literatura Española e Hispanoamericana) por la Universidad de Salamanca. En 2015, estuvo de Erasmus en la Universidad de La Rioja donde estudió Filología Hispánica durante 9 meses. Formó parte del grupo de investigación, Cognitive modeling and meaning construction across languages: theory, implications, and applications, coordinado por la Universidad de La Rioja. Actualmente acaba de realizar el Máster en Estudios Avanzados en Filosofía (especialidad en Estética y Teoría de las Artes) en la Universidad de Salamanca, con el propósito de acceder al Doctorado.
} 


\section{Introducción}

Como su título indica, el objeto de nuestro estudio reside en reflexionar sobre el concepto de «metáfora» en la novela Bestiaria vida de Cecilia Eudave, galardonada con el Premio Nacional de Novela Corta «Juan García Ponce» en 2008. La pregunta central que conducirá nuestro análisis es: ¿Se puede hablar de metáfora como un elemento de deconstrucción de ideologías en Bestiaria vida? O, dicho de otro modo, ;es la metáfora, en Bestiaria vida, no solo una figura literaria que expresa un contenido oculto, sino también, un sistema de representación para desenmascarar una ideología social que se ha venido edificando y que, como bien señala Byung-Chan Han en La sociedad del cansancio, convierte al hombre en «sujeto de rendimiento»?

Para empezar, no hay que entender la metáfora como un simple recurso de la retórica clásica, es decir, como rasgo del lenguaje que tiene la función de sustituir un significado propio por uno figurado. Según lo que Lakoff y Johnson afirman en Metáforas de la vida cotidiana, la metáfora "impregna la vida cotidiana, no solamente el lenguaje, sino también el pensamiento y la acción. Nuestro sistema conceptual ordinario, en términos del cual pensamos y actuamos, es fundamentalmente de naturaleza metafórica» (Lakoff y Johnson 39). El lingüista y el filósofo conciben el ser humano como un sistema que actúa de forma autónoma y automática, conforme a un lenguaje que no solo dicta normas, sino que también engloba una imagen, un contenido, un concepto metafórico que influye en nuestra vida cotidiana ${ }^{1}$.

En este sentido, el autor de La inteligencia reformulada: las inteligencias múltiples en el siglo XXI, Howard Gardner, señala que el individuo dedica mucho tiempo de su vida a decodificar sistemas de símbolos que diariamente le dominan y que son reflejo de la cultura en la que vive, desarrollando,

1. En «El uso trascendental de las metáforas en la ciencia», el catedrático de Historia de la Ciencia y Estudios Humanísticos en la Universidad de Wisconsin-Green Bay, David Galaty afirma que una determinada palabra engloba a un conjunto de contenidos implícitos. Galaty hace el ejemplo de la palabra "perro» que recoge no solo los perros presentes sino también los pasados y aquellos futuros, estableciendo así una clase de animales inmaterial pero rica de contenido. En definitiva, dicha palabra no es sino un modelo metafórico: «perro expone que un animal en particular es la representación de una idea de perro» (Galaty, 78-79). además, una mente capaz de traducir significados sensibles que se manifiestan por medio de símbolos, metáforas y analogías. El cerebro humano, asegura Gardner, ha evolucionado «para procesar con eficacia determinados tipos de símbolos» (57-58).

Lo había expresado, también, el precursor del estructuralismo, Ferdinand de Saussure cuando definió el lenguaje como la dicotomía biunívoca entre significante y significado: en el primero se produce la imagen acústica (todo lo que se puede oír o ver); en el segundo, en cambio, se origina la imagen mental en la que se sitúa la cultura del individuo y que aporta una intensificación de significado que es, desde luego, un enriquecimiento para el individuo (Saussure 137). Imagen mental que no solo es reflejo de un mundo simbólico, representacional, derivado de nuestro entorno, sino también abstracto, lleno de objetos imaginarios e indefinidos. Estos objetos nos facilitan el acceso a un tipo de conocimiento inmaterial, subversivo, perturbador y desestabilizador el cual solemos llamar el mundo de la fantasía ${ }^{2}$. Ahora bien, si la fantasía es un producto sofisticado de la realidad, una imagen mental, un símbolo alterado que se origina de lo que nos circunda, se hace necesario preguntarnos sobre la manera en que la fantasía se pone en contacto e interactúa con la realidad.

En este sentido, la metáfora toma el papel de protagonista. Durante una de sus clases de literatura, Julio Cortázar señalaba: «la fantasía, lo fantástico, lo imaginable que yo amo y con lo cual he tratado de hacer mi propia obra es todo lo que en el fondo sirve para proyectar con más claridad y con más fuerza la realidad que nos rodea» (Cortázar 81). Conforme a lo anterior, vale la pena destacar la aportación del teórico y escritor Harry Belevan, según el cual lo fantástico sería como una siñalética en el sentido de

2. En la tercera edición del Congreso Spoletociencia de 1991, Jerome Bruner emprende un interesante análisis acerca de cómo percibimos el mundo que nos circunda. Este psicólogo, retomando varios experimentos con bebes realizados por William Kessen, Alan Leslie o Andrew Metzoff, concluye que es difícil diferenciar entre lo que conocemos y de qué manera lo describimos. Tengamos en cuenta, asegura el psicólogo cognitivo, que el individuo confunde el mundo humano regulado por las creencias, deseos o expectativas con el mundo natural dominado por principios de causalidad y determinismo. Este caos se origina, sobre todo, durante los primeros ańos de vida donde, probablemente, reside esa visión de un mundo prefabricado, una mera invención y constructo teórico, un producto de la imaginación y acto ilusorio (Bruner 129-142). 
que se manifiesta bajo forma de señales y síntomas - metáforas, analogías, simbologías-, que provocan al lector una vacilación, una dubitación de lo que está leyendo; en otras palabras, lo fantástico no hace más que causar una alteración, "un cortocircuito entre el lector y el material textual» (Belevan 113). El mismo Belevan decía: «yo creo que la característica de lo fantástico es que debe estar [sic] parte de la realidad; o sea, se inicia en la realidad llana, real y termina en la realidad real» (Belevan, «La naturaleza de lo fantástico»). Es decir, la fantasía está constituida por un espacio de hechos cotidianos que se trastocan, se quiebran y pasan a otra realidad sofisticada, alterada, profanada, que no es sino una realidad fabricada e inventada por el ser humano.

Llegado a este punto, para entender la fantasía parece incuestionable la necesidad de acudir a nuestro entorno, al contexto lingüístico y a nuestra experiencia. David Roas señala que nuestra interacción modifica la naturaleza de lo que observamos. "De ese modo, la realidad deja de ser objetiva y 'externa', pues se ve profundamente afectada por el individuo que interacciona con ella» (Roas 96). Por consiguiente, la experiencia del individuo nos abre la puerta hacia mundos constituidos por códigos que subvierten las leyes naturales; mundos sofisticados que funcionan por medio de simbologías, alegorías, metáforas, $y$ que fomentan la libertad imaginativa del lector. Esta libertad imaginativa podría ser absurda e inadmisible si en realidad, lo que nos circunda no fuera tan abrupto y caótico como lo es.

En «Las metáforas literalizadas y otros procedimientos de lo fantástico en distintos libros-álbum», Sergio Etkin y Flavia Krause recogen una interesante ponencia que la profesora y teórica de lo fantástico, Ana Casas, presenta en un Coloquio Internacional de Estudios Hispánicos. Casas señala tres ámbitos lingüísticos que favorecen la transgresión fantástica en un texto discursivo: la impertinencia semántica o yuxtaposición de campos semánticos desvinculados, la literalización de la metáfora y la ubicuidad de los deícticos. Con respecto al segundo ámbito, Etkin y Krause señalan:

La literalización de la metáfora como recurso de lo fantástico tiene, sin embargo, un antecedente más lejano en Todorov y está determinada por su unidad estructural y por ser un rasgo definitorio del género la vacilación que pone en escena entre interpretar los hechos narrados sobre la base de las leyes naturales o tomarlos como acontecimientos sobrenaturales (Etkin y Krause 104).
Avanzando en nuestro razonamiento, es evidente que cuando hablamos de metáforas fantásticas nos referimos no solo a un rasgo definitorio del lenguaje sino también a un sistema conceptual de significaciones que trastornan y desnaturalizan lo real, permitiéndonos la entrada en un sistema ficcional autónomo que no es sino un reflejo de lo que nos circunda. Así pues, ya no hablamos — según Jackson - de una desnaturalización del elemento fantástico o extraño (Jackson 41) sino que nos referimos a una naturalización de lo sobrenatural; es decir, se registra como natural y se establecen construcciones alegóricas, metafóricas o simbólicas que alteran lo fantástico volviéndolo más real y natural. Lo anterior se esclarece en aquello que la catedrática de la Universidad de Alicante, Carmen Alemany Bay, ha llamado como "narrativa de lo inusual», categoría que otorga a la novela Bestiaria vida de Cecilia Eudave:

La narrativa de lo inusual vendría a ser una mezcla híbrida de la representación de la realidad tradicional y una realidad insólita, su síntesis. Si la realidad es la tesis y lo insólito su antítesis, la síntesis sería la realidad inusual que trata de sintetizar, de armonizar los opuestos: un péndulo que oscila entre lo insólito y la realidad convencional o convenida. Ahora bien, si en lo fantástico lo real está al servicio de este; en los textos inusuales lo fantástico está al servicio de lo real (Alemany Bay, «Prólogo» 11).

Así, lo inusual configura universos narrativos que son «sistemas de representación metafórica y que intentan revelar las emociones ocultas detrás de las circunstancias cotidianas» (11). De este modo, se van construyendo mundos insólitos en los que las huellas del pensamiento creativo e imaginativo no son lo suficientemente resistentes como para trastornar la realidad tal como la conocemos. Dicho de otro modo, si bien es cierto que estos universos narrativos producen sentimientos de extrañezas y de incertidumbres como inquietud y sospecha; el punto de llegada no es situarse en un contexto estrictamente fantástico sino en una condición de tránsito, en ese pasaje de un punto a otro, de la fantasía a la realidad dañada y contaminada en la que todo puede ocurrir. Estos universos se ubican donde las leyes naturales se ven perturbadas pero sin ser «hundidas» por las más terribles fauces de lo fantástico.

En ese sentido, toma mayor fuerza la subjetividad y la percepción del observador a la hora de leer un cuento inusual que, según señala Alemany Bay, «es capaz de angustiarnos y que no nace de lo observado 
sino de lo sentido, un realismo que se apuntala en las grietas de este concepto para ser sustituido por la capacidad de sugerencia de lo real» (14). Por tanto, dicho realismo sugiere no solo un cambio de mirada, sino también un replanteamiento de nuestra existencia. Nos cuestionamos de dónde venimos, quiénes somos, nuestra condición humana profunda y, en parte, desconocida. Esta condición humana resulta inquietante y amenazadora, producto de un realismo que reconstruye la imagen desconcertante de nosotros mismos.

En este contexto, la metáfora se mueve en los límites de lo imposible y explora los límites fronterizos entre lo real y lo fantástico. En La metáfora: ensayos transdisciplinares, el catedrático de la UNED, Eduardo Bustos, se refiere a la metáfora como el recurso que «extiende la proyección entre sus asuntos, forzando los límites expresivos del lenguaje» (287). La metáfora no hace más que invitar al lector a una trascendencia cognitiva; es decir, a cruzar, a trasponer la línea fronteriza, una línea trasgresora que traslada al ser humano a otro lado, hacia otra realidad o, según las palabras belevianas, de la «realidad llana» a la «realidad real».

\section{La representación metafórica en Bestiaria vida}

Somos bestias contenidas en laberintos sociales, intentando encontrar nuestro lado más humano

Cecilia Eudave

Sin embargo, todas estas observaciones nos ofrecen una portada especial para analizar el caso de la mexicana Cecilia Eudave con su célebre novela Bestiaria vida, publicada, por primera vez, en Yucatán en 2008 y en España en septiembre de 2018. El ejemplo de Eudave nos ayuda a penetrar en la cuestión que se planteaba al comienzo de este trabajo: es decir, que la narración por metáforas es en sí misma una estrategia al que el escritor recurre para desenmascarar una ideología social. Es decir, un sistema de representación metafórica que tiene como fin no solo representar el mundo externo sino también dar a conocer aquella parte del ser humano corrompida por una sociedad embriagadora, aquella parte que resulta ajena, oculta y en parte desconocida.

En «El monstruo como instrumento cognitivo y último refugio ante el mundo. Acercamiento a Bestiaria vida de Cecilia Eudave», Juan Tomás Martínez Gutiérrez comenta: «es necesario tener en cuenta que la narración se presenta codificada como una novela realista. Los monstruos no existen en un sentido literal» (Martínez Gutiérrez 132); y aún más acertado es lo que, en «Bestiaria vida o la vida en las alfombras», Carlos Martín Briceño reconoce: «no es un relato netamente fantástico; es más bien un texto de realidades alternativas; [...] tiene célebres e imaginativos pasajes fantásticos que, además de provocar la risa franca del lector, inquietan, de tan bien construidos» (Briceño, «Bestiaria vida o la vida...»). Terminamos con las palabras claves que, en una entrevista, realizó Carmen Alemany a Cecilia Eudave en la que afirmó: «Esa forma mía de representar de manera diferente la realidad que me aqueja, $[. .$.$] otra forma de leer la realidad a través de$ analogías, metáforas y otros mecanismos que, insisto, me sirven para representar la realidad» (Alemany Bay, «Narrar lo inusual...» 117).

No cabe duda de que la escritura eudaviana se caracteriza por una estructura dúctil, capaz de representar tanto lo inexplicable como lo imaginable, lo impenetrable y lo inteligible. Una escritura en condiciones de habitar y describir espacios paralelos, mundos alternos e insólitos que remiten no solo al ámbito fantástico sino también mitológico; una escritura cuya madurez la lleva a estar cómoda tanto en el espacio real como en lo fantástico, a permear y transitar, a extraviar la vida real y personificar seres de otras realidades. Cabe señalar que todo esto Cecilia Eudave lo logra con su concisión. Eudave trabaja con metáforas y analogías que, indudablemente, tienen la función de seducir al lector y traerlo, en los momentos de distracción, a procedimientos imaginativos. Su escritura se singulariza por un estilo sencillo, directo, preciso y natural, a veces poético; una escritura cuya brevedad economiza el texto y lo hace más próximo al lector. Por otra parte, la brevedad es uno de los rasgos del siglo XXI que ejerce una particular fascinación y magnetismo con el lector - recordemos las Seis propuestas para el próximo milenio de Italo Calvino-. En ese sentido, en una entrevista por Ricardo Solís, Cecilia Eudave afirma: "Los textos hiperbreves me demandan mucho más. Es un género demandante, pues tiene que ser muy redondo para que funcione; porque debe ser atractivo, se tiene que economizar mucho con el lenguaje, ser muy claros con las imágenes [...]» (Solís apud Noguerol 61).

Lo dicho hasta aquí no es sino el esqueleto de la escritura eudaviana a través de la cual ella revela y expresa una realidad inusual. Esta se muestra como un reflejo de la condición humana en la que los nebulosos obstáculos de la vida real se ven fragmentados 
para dejar espacio a la libertad imaginativa. En este sentido la mexicana define lo fantástico:

Como una herramienta para evidenciar las problemáticas del ser humano sin hacer uso necesariamente de lo «real». Finalmente todo es ficción, representación, y a veces yo privilegio una manera más «inusual» para hablar de las realidades que nos circundan. La verosimilitud está un poco descontextualizada cuando se introduce el término en la literatura, todo es verosímil si el universo que la contiene se sostiene y da al lector la posibilidad de vivir bajo esas reglas y con esa óptica. En lo fantástico, la metáfora o la analogía sirven para crear correspondencias mucho más estremecedoras con la realidad (Eudave 2016).

Cabe señalar que los personajes de la novela estructuralmente son verosímiles gracias a un universo que se presenta como real. No hay que olvidar que se está hablando de individuos (la madre, el padre, la tía, sus abuelos) que se mueven en espacios narrativos de naturaleza realista, como el jardín, la habitación, la casa y el lugar del trabajo que, desde luego, nuestro cerebro categoriza como si fuesen reales. Por un lado, Eudave les añade características y propiedades físicas y comportamentales mitológicas, fantásticas y macabras que los convierten en metáforas fantásticas, personajes irreales. Por otro lado, los hace verosímiles por el universo real que los rige. Algunos ejemplos son el personaje de Mamá Basil cuya «mirada es capaz de matar a la gente», incluso a sí misma: "Cómo miraba mi madre. Debía cuidarse al pasar frente a los espejos. Si ella llegaba a verse a sí misma como nos miraba a nosotros, seguro ahora estaría muerta» (Eudave 16); el cancerbero que corresponde al abuelo que cuida la puerta del infierno; o el búfalo extraño que responde a su tío "que de tanto mirar para abajo, tenía una giba» (21).

Por consiguiente, cuando en «La conciencia de los topos» se cuentan las percepciones que la protagonista tiene con respecto a los topos - lo que sería en realidad inverosímil - se vuelve posible gracias a un universo escritural que lo soporta: «acostumbrada como estoy a las pesadillas, pronto comprendí que, en cierto sentido, no son tan horribles como la realidad. Por ello, cuando sońé aquella noche que me levantaba convertida en un enorme hueso sobre mi cama, no me sorprendí» (38).

Así, estamos de acuerdo con Carmen Alemany Bay, quien afirma que los personajes actúan de manera consciente y que detectan tránsitos «a otras realidades; universos complejos, ambiguos, ante una realidad trastocada por la imaginación o por la desestabilización de quien lo enuncia y que está haciendo una reinterpretación de la realidad a partir de esos parámetros» (Alemany Bay 115). Además, queremos subrayar que Cecilia Eudave hace de un bestiario tradicional, hostil y fantástico, una realidad en la que los personajes - representados metafóricamente en la narración bajo la forma de licántropos, basiliscos y cancerberos- se afirman como seres reales y humanizados, producto de una sociedad exasperada y ahogada en un vendaval de histeria silenciosa. Esa estrategia de representación metafórica es la que revela las emociones ocultas del ser humano y que permite el acceso a un mundo, espejo y reflejo de lo real, pero al mismo tiempo, alterado, trasgredido y profanado. De aquí, se genera un discurso ficcional por medio del cual el lector se cuestiona si lo que está leyendo podría ocurrir en la realidad, una especie de mareo embriagador persistente en toda la novela que está acentuado por recursos retóricos que dejan ver lo que no se alcanza a decir.

Por otra parte, en Estudios sobre argumentación: teoría y práctica, Eduardo Bustos nos recuerda que para que se produzca el vértigo argumental, uno de los recursos que poseemos es la analogía, proceso que permite ampliar el argumento (Bustos 86). En esta dirección, podemos pensar en las analogías - metáforas incluidas - como la acción no solo de crear nuevos espacios, de proyectar y extender aquella realidad posible que nos acomuna a todos; sino también una estrategia discursiva que intercepta una ideología apuntalada en las grietas de nuestra sociedad y de nuestro tiempo. Nos referimos al término ideología en su sentido interdisciplinario, o sea, social, económico, político, tecnológico, psicológico. De igual manera, se emplea el mismo sentido en la obra $\mathrm{La}$ dimensión politica de lo irreal: el componente ideológico en la narrativa fantástica española y catalana de Alfons Gregori que hace la distinción entre lo inverosímil y lo ideológico. Parafraseando, el primero es el que, en vez de ser advertido como sobrenatural, se percibe «desconcertante», «desquiciado» o "accidental», desestabilizando la idea que se poseía anteriormente. En cambio, el segundo se manifiesta en procedimientos verosímiles que, habitualmente, no traicionan las expectativas de los lectores (Gregori 451-452). Según las palabras de Gregori:

En el marco de la posmodernidad, es mucho más probable, literariamente hablando, que un vampiro se dedique a chupar la leche de los pechos de mujeres que amamantan a sus bebés que un sindicalista vaya 
pensando por la calle en lo bueno que es el jefe de la empresa que cada vez paga menos, o que una ama de casa británica de clase alta haga colección de fotos de Stalin mientras elabora discursos leninistas para los mineros en huelga. Lo ideológico, en este sentido, suele funcionar como punto de referencia de lo convencional, un punto de apoyo en la realidad representacional, para que el texto fantástico o maravilloso no pase a otra categoría estética, que sería normalmente lo absurdo (452).

Vale la pena destacar también que, en La sociedad del cansancio, Byung-Chan Han señala el siglo XXI como el siglo del agotamiento, la depresión, las enfermedades neuronales; también es el siglo de los infartos psíquicos y de las manifestaciones de violencias neuronales, las fatigas y las asfixias: un torbellino anímico derivado de un exceso de positividad. El ser humano actual pertenece a una época histórica en el que la producción, la información y la comunicación se han potenciado enormemente, hasta llevar a la sociedad de disciplinada a una sociedad de rendimiento ${ }^{3}$.

Este cambio de paradigma, no por casualidad, se refleja en una reciente entrevista por correo que Cecilia Eudave concedió:

De ahí que surja una nueva forma de narrar, entre un grupo de escritores que sin ser grupo, comparten esta perspectiva: la narrativa de lo inusual, que propone Carmen Alemany Bay. Y que finalmente ya venía anunciando nuestro repudio a ser solo sujetos de rendimiento, viviendo para ascender socialmente, despersonalizados; lo que ahora se puso de moda, dos décadas después, de la mano del filósofo surcoreano Byung-Chul Han (Eduave 2019).

A la vista de los argumentos expuestos en el presente artículo, pensamos que Bestiaria vida se hace portadora de la soledad anímica en la que vive el ser humano, una denuncia que Cecilia Eudave lleva a cabo de forma magistral y que esconde una ideología social. Por esta se entiende una ideología que lleva al hombre a convertirse, como dijo Byung-Chul Han y como bien seńala Carmen Alemany Bay, en «sujeto

3. El filósofo y ensayista surcoreano esclarece esta dicotomía social de la siguiente manera: "A la sociedad disciplinaria todavía la rige el no. Su negatividad genera locos y criminales. La sociedad de rendimiento, por el contrario, produce depresivos y fracasados» (Han 17). de rendimiento» ${ }^{4}$. Este individuo es un ser dominado por el capitalismo, el globalismo, la histeria de los sistemas de producción e industrialización. Lo anterior provoca no solo un trastorno del sistema sino también una extenuación del sujeto mismo que sobrevive a la monstruosidad del presente. Así, en Bestiaria vida la trasgresión de lo cotidiano se convierte en una oportunidad para criticar la sociedad que agota el ser humano: una trasgresión que se hace aún más estremecedora si pensamos que Eudave construye la trama en torno a la familia, columna vertebral de nuestra sociedad. Así, en una entrevista de José Daniel Espejo, Cecilia Eudave asegura con respecto a la familia:

Es el primer núcleo que forma la sociedad en la que nos vamos integrar y es la que nos prepara para sobrevivir, para bien o para mal, en la jungla social. Cambian los escenarios, las modas y costumbres, las tendencias políticas, las esferas ideológicas y sus prácticas sociales, pero los hombres y mujeres siguen siendo seres de natura que deben enfrentarse a todo lo antinatural: la industrialización, la globalización, con sus sistemas de competencia y el terrible estrés convirtiéndonos en "abominables hombres del trabajo», al igual que todo aquello que se va gestando para domesticar nuestra naturaleza (Espejo 2019).

Baste como se muestra en el relato «El abominable hombre del trabajo» en el que el padre de la protagonista (Licántropo) está acechado por un repugnante y pútrido hombre que se instala en su conciencia y que es metáfora no solo de su otro yo sino también de una sociedad hundida del cansancio infinito: «Enorme, gris, con esa mirada vacía que parece contener todo el cansancio el resentimiento y la ira del mundo» (Eudave 69).

De igual modo, en el capítulo "Cocodrilos en aguas azarosas», la protagonista reflexiona acerca de nuestra condición humana situada en un mundo donde la locución latina hobbesiana Homo homini lupus parece ser tan verdadera como real, metáfora de una sociedad competitiva:

4. De manera semejante, el autor de Ensayos sobre el posmodernismo, Fredric Jameson señala: «El comienzo de un tipo completamente nuevo de sociedad, cuyo nombre más famoso es el de "sociedad posindustrial" (Daniel Bell), pero en la que a menudo se designa bien con los títulos de sociedad de consumo, sociedad de los medios masivos, sociedad de la informática, sociedad electrónica o de la tecnología sofisticada» (Jameson 17). 
Somos una nota insólita en este anuario de gente que cada ańo celebra nacimientos y muertes. Y al final, sólo quedas tú con tu empolvada vida. Cuando eres niña no piensas en nada de esto. Crees que el mundo en el que vives es de naturaleza noble. Luego lo descubres inhóspito y ruin. Es un gran escenario donde debes enfrentarte a tus iguales y resistir sus embestidas. Crecer, sobrevivir, reproducirte y finalmente esperar a no morir en manos de alguna circunstancia histérica y entaconada (Eudave 53).

En este sentido, no se equivocaba Jordi Agustí cuando, en La evolución y sus metáforas: una perspectiva paleobiológica, declaraba que el progreso evolutivo está conectado con el progreso como sobrevivencia, al respecto asevera: «Hay que avanzar más que los demás para no perder la plaza, la casilla» (Agustí 60). Esta lucha provoca un agotamiento del personaje en Bestiaria vida, un colapso psicofísico que se vuelve visible desde las primeras páginas a través de un lenguaje tan preciso como fragmentario: «Se me acabaron las fuerzas [...]. Así estoy, en la cama, sin deseos de nada. Me cuesta levantarme. Abro un ojo, luego el otro, intento estirar una mano para ayudar a la otra a ponerme en pie. Nada. Vuelvo a caer [...]. Silencio. Eso sería lo mejor» (28).

Y aún más explícita es la protagonista en el relato "Los demonios desordenados» cuando dice de sí misma que «siempre estaba triste, entumecida, arrinconada y desganada» (86) o cuando recuerda el personaje de Lucio metido en el alcohol y la marihuana, lacras de nuestra sociedad:

La verdad es que desde hace tiempo solo piensa en beber, su único objetivo en esta vida es beber y su último fin es beber. La marihuana es solo para protegerse de la histeria, para suavizar la profunda tristeza que se acumula día tras día en la cabeza. ¿Quién no está así? A ratos el mundo entero parece un enorme sollozadero. No hay dónde esconderse, entonces ¿por qué esconderse? (83).

Este cansancio corporal, conforme a lo anterior, se transforma así en una metáfora de la sociedad que nos obliga a hacer lo que no queremos, que oscurece nuestras íntimas y verdaderas subjetividades para sustituirlas con otras prefabricadas, hijas de una lógica posmoderna. En una reciente entrevista, Cecilia Eudave retoma lo que Anadeli Bencomo señala con respecto a las subjetividades anómalas que se expresan dentro de la novela corta de finales del $\mathrm{xx}$ y comienzos del siglo $\mathrm{XXI}^{5}$. La profesora $\mathrm{y}$ crítica literaria de la Universidad de Houston sostiene que los personajes de esta narrativa breve son figuras antiheroicas, individuos anómalos, pues representan un tejido social y unas circunstancias posmodernas decadentes. Haciendo referencia a Giorgio Agamben, Bencomo asevera: «individuos cuya existencia queda fuera de la categoría cívica de los derechos políticos, haciéndolos prescindibles y descartables» (Bencomo 28). Esta lógica convierte al humano en un ser animalizado. De ahí, uno de los tantos rasgos que caracteriza la narrativa eudaviana: el pasaje de lo humano al animal, cuya síntesis es la bestialización. Como vemos en el siguiente pasaje:

Estoy mejor ahora, arrumbada en mi sillón, recordando mis pesadillas y comiéndome la vida tan despacio que nadie recordará que pasé por aquí. Mejor así. Mejor seguir ignorando al miedo, aunque esté aquí, sentado en este mismo sillón, compartiendo sus proezas con los fantasmas que él me ha sembrado por el camino. Mejor seguir bajo el agua, sacando los ojos apenas como lo hacen los cocodrilos, sin olvidar el instinto de conservación para evitar el taconazo entre las cejas. ¿¿Mejor? (Eudave 56).

Como podemos comprobar, la protagonista de Bestiaria vida está agotada, sufre una especie de depresión que la obliga a quedarse en el umbral y a refugiarse en la dimensión animal. Esta condición encaja con el análisis del filósofo surcoreano sobre la humanidad, la cual está en guerra consigo misma y produce sujetos depresivos cuyos lamentos habitan en una sociedad que cree: «Nada es imposible» (Han 19). En "Leones cazando bestias en el parque», se cuenta la noticia de un padre que había matado a su hijo porque no le dejaba descansar. Así pues, cuando la protagonista levanta los ojos y se detiene a mirar a las otras personas que le rodeaban, lo que ve es:

Gente que iba y venía por el parque, paseando a sus hijos, futuras bestias; ancianos abandonados en las

5. Reportamos las palabras de Cecilia Eudave: «Estoy de acuerdo con Anadeli Bencomo — que también se ha acercado críticamente a la novela_-, cuando habla de «subjetividades anómalas» propias de la narrativa de finales del xx y principios del siglo XxI, en donde me incluye junto a otros escritores. Ella se refiere a este fenómeno donde el sujeto social encubre al individuo creando figuras antiheroicas, buscando señales para librar las batallas personales, expulsados del nuevo paraíso prometido» (Eudave 2019). 
bancas buscando sol; parejas abrazándose ajenos a los ojos morbosos que se preguntan si son novios o amantes, porque se ven demasiado unidos para ser esposos, y cuando se despiden, cada cual se va por su lado. Gente que igual no tiene, o no cree tener, nada de culpa sobre las atrocidades que circundan el mundo; que está allí viviendo su vida, porque les tocó hacer esto o ser aquel, y que llevan sus destinos como pueden (116-117).

Creemos que aquí se esconde la verdadera sustancia de nuestra tesis sobre la «ideología social» enlazada a la estructura posmoderna de la metáfora eudaviana. Este escenario desolador, pintado por Eudave, se traduce en una gran dicotomía. Por un lado, el deseo del ser humano para encontrar su verdadera parte humana; por otro, descubrir que somos solo demonios desordenados, futuras bestias salvajes en una sociedad que es instintiva e irreflexiva y que, según las palabras de Eudave, «maquina nuevos modos de tortura existencial, llevándonos a suponer que son nuestros» (Eudave 2019). Esta tortura existencial de la que habla Cecilia Eudave se halla también en el tejido de las relaciones familiares que no son sino metáforas de nuestra sociedad. Relaciones que dominan y oprimen, aniquilan y devoran al individuo llevándolo a una neurosis colectiva o a un estado de desierto interior. Lo dicho se esclarece con el episodio de los familiares de la protagonista que creen ver gente chiquita en las alfombras y que, irremediablemente, terminan en una búsqueda compulsiva sin éxito, una fobia familiar hacia las alfombras que provoca una especie de obsesión o evasión:

Dejó de lado el proyecto del negocio, comía poco, no hablaba con nadie. Su única tarea era descubrir a esos malditos seres que habitaban su alfombra, o en todas las alfombras, llegó a decir. Tu abuelo entró en pánico. [...] Se lo llevaron, lo encerraron como al bisabuelo, a la bisabuela y cabe mencionar que nunca salió de allí. Ahora, cuando llega a algún lugar donde las hay, ve todo el tiempo hacia otro lado, no quiere pensar que si mira de reojo, estarán allí (Eudave 49).

La postura anterior se destaca en el relato «Sin oráculos no hay serpientes ni destino" en el que la tía Irene le revela a la protagonista la confesión que le hizo su padre en una cabaña durante una de las muchas escapadas que hacían:

Allí era otro, allí me dijo que siempre tuvo la sensación de ser un huérfano, de estar solo, completamente solo en el mundo. Buscando, buscando aunque sea a uno mismo. Y esa búsqueda de sí le confirmó lo desolados que estamos, pues nadie te dirá en dónde hallarte, porque no hay nadie a quien preguntarle, ni siquiera a ti mismo (Eudave 94-95).

Lo anterior condensa esa dicotomía que se mencionaba en las líneas anteriores. La insólita y paradójica toma de conciencia de que estamos solos en medios de un mundo rodeado de personas felices, pero quizá carentes de humanidad: bestias. Sin embargo, Cecilia Eudave no termina de sorprender al lector con un final cautivante e inesperado. En el último capítulo, -el más corto de la novela-, la protagonista acude a la llamada de su hermana que, sin ofenderla ni recriminalrle algo, le ruega ayuda. Esta postura testimonia un momento de ternura familiar, se deja atrás la situación de rivalidad fraternal que se observa desde las primeras páginas de Bestiaria vida, llegando a una especie de reconciliación entre las dos hermanas: «No te preocupes, Susana, voy para allá, no estás sola». $\mathrm{Y}$ es verdad, no lo está, yo la quiero, realmente la quiero» (125).

\section{Conclusiones}

Para concluir, como se ha podido observar a lo largo de este artículo, la metáfora parece ser algo más que un simple recurso lingüístico. Lleva en sí misma una fuerza profundamente poderosa que desenmascara lo real y deconstruye su ideología social para después establecer un escenario narrativo que actúa como filtro entre la realidad, cualquiera que sea, y el lector. En este sentido, Bestiaria vida se configura en este horizonte donde la metáfora deja ver la idea de una sociedad competitiva, agotadora, oprimente; una ideología producto de nuestra sociedad posmoderna que trastorna los valores humanísticos para que triunfe una sociedad en depresión.

\section{Bibliografía}

Agustí, Jordi. La evolución y sus metáforas: una perspectiva paleobiológica. Barcelona: Tusquets Editores, 1994.

Alemany Bay, Carmen. "Narrar lo inusual: Bestiaria vida de Cecilia Eudave y El animal sobre la piedra de Daniela Tarazona», Romance Notes, 56:1, (2016): 131-141.

Alemany Bay, Carmen. «Prólogo». En Eudave, Cecilia. Bestiaria vida. España: Eolas Ediciones, 2018. 
Belevan, Harry (2013), «Harry Belevan (Parte 4): La naturaleza de lo fantástico», entrevista por Rothgiesser, Hans. Consultable en línea en la página web: https:// www.youtube.com/watch?v=7wqs7KEckN4.

Belevan, Harry. Teoría de lo fantástico. Barcelona: Anagrama, 1976.

Bencomo, Anadeli. «La novela corta mexicana: relato antiépico y subjetividades anómalas». Anadeli Bencomo y Cecilia Eudave (eds.). En breve: La novela corta en México. Guadalajara, México: Universidad de Guadalajara, 2014, 28.

Briceño Martín, Carlos, «Bestiaria vida o la vida en las alfombras», Al final de la vigilia, 2010. Recuperado de: https://carlosmartinbriceno. wordpress.com/2010/07/16/bestiaria-vida-o-la-vidaen-las-alfombras/.

BRUner, Jerome. «Derecha e izquierda: dos maneras distintas de activar la imaginación». Preta, Lorena (ed.). Imágenes y metáforas de la ciencia. Madrid: Alianza, 1993, 129-142.

Bustos, Eduardo. Estudios sobre argumentación: teoría y práctica. Madrid: Cátedra, 2014.

Bustos, Eduardo. La metáfora: ensayos transdisciplinares. Madrid: Fondo de Cultura Económica, 2000.

Casas, Ana (2010), "La transgresión lingüística y el microrrelato fantástico» apud Etkin, Sergio y Krause, Flavia (2011), «Las metáforas literalizadas y otros procedimientos de lo fantástico en distintos librosálbum». En Una literatura sin fronteras, Universidad Nacional de La Plata, Editorial Artdigital. Consultable en línea en la página web: http://jornadasplan.fahce. unlp.edu.ar/iii-jornadas-2011/Actas\%202011.pdf.

Cortázar, Julio. Clases de literatura. Buenos Aires: Alfaguara, 2013.

De Saussure, Ferdinand. Curso de lingüistica general. Buenos Aires: Editorial Losada, 1945.

Espejo, Daniel José (2019), «La familia siempre ha sido muy cruel y feroz». En El Diario. Consulta en línea en la página web: https://www.eldiario.es/murcia/entrevistas/familia-siempre-feroz-cruel_0_872113845. html.

Eudave, Cecilia. Bestiaria vida. España: Eolas Ediciones, 2018.

Eudave, Cecilia. "Entrevista a Cecilia Eudave. Bestiaria vida: una novela de lo inusual». Simone,
Marino-Cicinelli. Orillas. ispanistica, 8, (2019): 265-272. Consultable en línea en la página web: http://orillas.cab.unipd.it/orillas/articoli/ numero_8/05Marino_arribos.pdf)

GaLATY, David. «El uso transcendente de las metáforas en ciencia». Margarita Vega, Carlos Eduardo Maldonado y Alfredo Marcos (eds.). Racionalidad cientifica y racionalidad humana, Valladolid: Universidad de Valladolid-Universidad El Bosque, 2001: 78-79.

GARDNER, Howard. La inteligencia reformulada: las inteligencias múltiples en el siglo XXI. Barcelona: Paidós, 2012.

Gregori, Alfons. La dimensión politica de lo irreal: el componente ideológico en la narrativa fantástica española y catalana. Poznań: Wydawnictwo Naukowe UAM, 2015.

HaN, Byung-Chul. La sociedad del cansancio. Barcelona: Herder, 2012.

JACKsOn, Rosemary. Fantasy: The Literature of Subversion. New Accents. Londres y Nueva York: Routledge, 1981.

JAMESON, Fredric. Ensayos sobre el posmodernismo. Buenos Aires: Ediciones Imago Mundi, 1991.

Lakoff, George y Johnson, Mark. Metáforas de la vida cotidiana. Cátedra: Madrid, 1986.

Marcos, Alfredo. Ciencia y acción. Una filosofía práctica de la ciencia. México: Fondo de Cultura Económica, 2010.

Martínez Gutiérrez, Juan. «El monstruo como instrumento cognitivo y último refugio ante el mundo. Acercamiento a Bestiaria vida, novela de Cecilia Eudave». Miguel Rodríguez Lozano (ed.). Nada es lo que parece: estudios sobre la novela mexicana, 20002009, México: UNAM, 2002: 132.

RoAs, David. «Lo fantástico como desestabilización de lo real: elementos para una definición». Teresa López Pellisa y Fernando Ángel Moreno (eds.), Ensayos sobre literatura fantástica y ciencia ficción, Madrid: Universidad Carlos III de Madrid, 2009: 94-120.

Solís, Ricardo (2011). «El microrrelato, un juego llevado al límite». En La Jornada de Jalisco, n.p. apud Noguerol, Francisca, "Heterocósmica en la minificción mexicana: el caso de Cecilia Eudave». Javier Franscisco Ordiz (ed.). Estrategias y figuraciones de lo insólito en la narrativa mexicana (siglos XIX-XX), Berna: Peter Lang, 2014. 